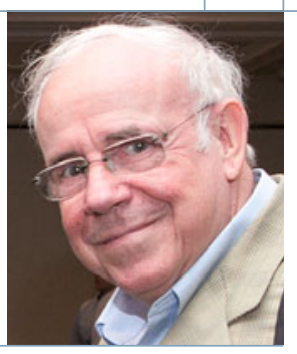

Ernst-Ludwig Winnacker

\title{
Der Brexit gefährdet den ERC
}

DOI: $10.1007 / \mathrm{s} 12268-016-0708-\mathrm{x}$

(C) Springer-Verlag 2016

Auf die negativen Folgen eines möglichen Brexit für die Forschung in Europa ist in den vergangenen Wochen vielfach hingewiesen worden. In diesem Zusammenhang sehe ich die möglichen Auswirkungen auf den Europäischen Forschungsrat (European Research Council, ERC) als geradezu katastrophal an. Wie keine andere Förderstruktur ist er auf das ausgelegt, was seit den 1970er-Jahren als „Europäischer Forschungsraum“ bezeichnet wird. Da wissenschaftliche Exzellenz in erster Linie durch einen Wettbewerb von Ideen entsteht, müsste diese umso größer werden, je größer der Forschungsraum ist. Forschungskommissar Ralf Dahrendorf hatte diesbezüglich schon 1973 darauf hingewiesen, „die Europäische Gemeinschaft könne und solle einen Beitrag dazu leisten, die Grenzen des nationalen Denkens in der Forschungspolitik zu überwinden und einen einzigen Europäischen Raum für die Forschung zu schaffen, in dem Zusammenarbeit und Wettbewerb einander auf sinnvolle Art und Weise ergänzen“.

Leider führte dieser Gedanke über ein gutes Vierteljahrhundert hinweg ein Aschenputteldasein, bis ihn die Staatschefs im März 2000 akzeptierten und unter anderem auch die Gründung eines ERC forderten. In einem Aide-Mémoire schrieb dazu Forschungskommissar Philip Busquin im Januar 2000: „Die Forschungspolitik der Mitgliedstaaten und die der EU laufen nebeneinander her, ohne ein in sich geschlossenes Ganzes zu bilden. Aus diesem Grund sind die unternommenen Anstrengungen oft umsonst."

Der Durchbruch für die Gründung eines ERC kam allerdings erst um die Jahreswende 2003/2004. Letztlich ging er auf eine Stellungnahme des damaligen Präsidenten der Royal Society, Sir Robert May, zurück, der mit größtem Nachdruck den Aufbau einer Institution forderte, die allein auf der Grundlage wissenschaftlicher Exzellenz zu arbeiten hätte, ohne jeden „juste retour“. Dem konnten am Ende alle Beteiligten zustimmen, auch und insbesondere die Europäische Kommission, und so nahm der ERC denn im Januar 2007 seine Arbeit auf. Heute, nahezu zehn Jahre später, gilt er als eine der prestigeträchtigsten Einrichtungen der Forschungsförderung in Europa, nicht zuletzt, weil auch die Kommission alles daran setzte, zunächst widerstrebend, dann aber aus ganzem Herzen, dem ERC zum Erfolg zu verhelfen.

Wissenschaftlerinnen und Wissenschaftler aus dem Vereinigten Königreich stehen heute an der Spitze der vom ERC geförderten Personen. Vom Geld her gesehen geht es allerdings nicht um allzu viel, um vielleicht 300 Millionen Euro, die im Prinzip die UKRegierung der Wissenschaft im Vereinigten Königreich auch aus dem eigenen Haushalt zur Verfügung stellen könnte. Anders als von den Brexit-Befürwortern behauptet, geht es aber nicht so sehr ums Geld, als um die Breite des Wettbewerbs. Je größer die Anzahl der Wettbewerber ist, desto weniger Interessenkonflikte gibt es, desto mehr gute Anträge werden vorgelegt und desto besser ist die geförderte Forschung. Dieses Konzept steht, wie erwähnt, am Ursprung des ERC. Britische Wissenschaftler würden nach einem Austritt nicht mehr im Wettbewerb mit dem Rest Europas stehen, sondern unter sich bleiben. Umgekehrt verliert der ERC einen Partner, der hervorragende Projekte einbringt, die nun nicht mehr zum Standard der wissenschaftlichen Exzellenz in Europa beitrügen. Am Rande sei hier nur vermerkt, dass auch der Austritt der Schweiz im Raum steht, deren Wissenschaftlerinnen und Wissenschaftler im Rahmen des ERC ebenfalls hervorragend abschneiden.

Welche Optionen lassen sich vor diesem Hintergrund erkennen?

Erstens: Auch wenn seine Verhandlungsposition in Sachen ERC entsprechend gut erscheint, sieht es derzeit nicht danach aus, als könnte das Vereinigte Königreich bei einem Brexit mit einer Sonderregelung für den ERC rechnen.

Zweitens: Ich könnte mir vorstellen, dass in den kommenden Monaten die wirtschaftlichen Rahmenbedingungen für einen Brexit so schlecht werden, dass die englische Regierung auf einen Antrag auf Austritt verzichtet. Davon würde dann auch der ERC profitieren.

Drittens wäre es denkbar, den ERC aus dem EU-Kontext herauszulösen und als eine selbstständige Einrichtung zu etablieren, ähnlich wie das CERN (European Organization for Nuclear Research) in Genf oder das EMBL (European Molecular Biology Laboratory) in Heidelberg.

Schließlich: Einen Rumpf-ERC ohne UK und ohne die Schweiz halte ich persönlich für nicht denkbar. Eine solche Lösung wäre das Ende des ERC, wie wir ihn kennen und aufgebaut haben. Es mag Leute geben, die sich angesichts des harten Wettbewerbs beim ERC über eine Erhöhung der Bewilligungsquote freuen. Im Sinne Europas als Forschungsstandort wäre diese Freude allerdings völlig fehl am Platz.

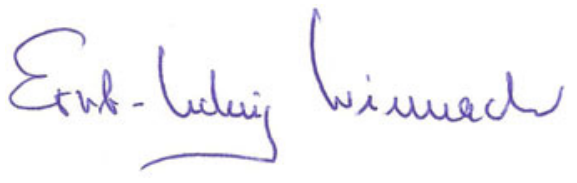

Ernst-Ludwig Winnacker, bis 2009 erster Generalsekretär des ERC

Korrespondenzadresse:

Prof. Dr. Dr. h. c. Ernst-Ludwig Winnacker Ludwig-Maximilians-Universität München Genzentrum

Feodor-Lynen-Straße 25

D-81377 München

Tel.: 089-218076734

elwinnacker@genzentrum.Imu.de 